\title{
Effect of Hollow Shape on the Behavior of Reinforced Self- Compacting Concrete Slender Column Under Eccentric Loading
}

\author{
Maha G. Ghaddar ${ }^{a^{*}}$ \\ ${ }^{a}$ Civil Engineering Department, University of Technology, Baghdad, Iraq, 40148@uotechnology.edu.iq \\ *Corresponding author.
}

Submitted: 19/09/2019

K E Y W O R D

Slender columns,

Hollow columns,

Eccentric loading,

Concealing PVC pipes.
Accepted: 01/02/2020

Published: 25/06/2021

\begin{abstract}
A B S T R A C T
Results of testing reinforced self-compacted concrete slender columns having longitudinal holes concealing PVC pipe in their cross sections under axial compression load and uniaxial bending are presented in this paper. The effect of hollow shape on the performance of slender columns having 200x200mm quadratic cross section and 1300mm long under concentric and eccentric loads was investigated. Three different shapes of central hole: circular, square, and lozenge pattern in addition to the different load eccentricity values were considered to investigate the axial loading resistance and cracking load, lateral and longitudinal deflections of the columns. Test results have showed that altering the hollow shape inside the area of column cross section does not show a great influence on the column behavior unless the hollow ratio changed. The effect of hole shape or the hollow ratio on loading capacity is insignificant but the existence of a hole embedded longitudinally in the column significantly decreases its ultimate capacity. The effect of hollow shape or hollow ratio on a slender columns behavior subjected to eccentric loading with small ratio of load eccentricity to total column thickness $(e / h=.33)$ was more than that of large eccentricity $(e / h=1.0)$. Accordingly, the decrease in loading column capacity of columns was $(5.0 \%, 2.5 \%$, and $6.6 \%)$ compared to $(3.2 \%, 2.2 \%$, and $4.7 \%)$ for the same hole shapes respectively.
\end{abstract}

How to cite this article: M.G. Ghaddar, "Compacting Concrete Slender Column Under Eccentric Loading" Engineering and Technology Journal, Engineering and Technology Journal, Vol. 39, No. 06, pp. 884-892, 2021.

DOI: https://doi.org/10.30684/etj.v39i6.1504

This is an open access article under the CC BY 4.0 license http://creativecommons.org/licenses/by/4.0

\section{INTRODUCTION}

Generally, making internally a longitudinal hole into the column has two fundamental interests in structural building: a decrease in the building weight and the facility to hide PVC tubes reinforced concrete columns for rainwater drainage, see Figure 1. Many studies concluded that the existence of a hole within the structural members will affect their bearing capacity and deformation relating to 
holes feature, concrete grade and reinforcing steel ratio utilized; Han et al. [1], Mohsen et al. [2], Murugesan and Narayanan [3]. Bakhteri and Iskandar [4] experimentally investigated the effect of positioning a rain drainage pipe inside reinforced concrete columns at the center of their cross sections. They found a significant decrease in loading capacity of the columns, and the obtained factor of safety differs from 1.2 to 1.59 , which is less than the nominal value of 2 as mentioned by the American Concrete Institution (ACI) code requirements.

Lignola et al. [5] and Yazici and Hadi [6] performed experimentally an investigation on the square hollow reinforced concrete short columns surrounded by carbon fibers reinforced polymer (CFRP). They found that the failure modes of members were highly affected by the happening of early mechanism of axially loaded members buckling and the spalling of concrete cover, and the CFRP confinements could delay this mechanism, consequently causing an increase in strength capability and ductility of such members, even in large eccentricity values. Galano and Vignoli [7] presented a study on high strength concrete (HSC) and self-compacting concrete (SCC) slender columns. They found that the SCC columns subjected to loading of small eccentricities caused lower normalized peak strength than the conventional vibrated columns for normal and high strength concrete, and the modes of failure revealed that the SCC columns prepared of normal strength concrete behave in a more ductile mode in comparison to other columns which were tested. Campione et al [8] investigated the performance of fiber reinforced concrete short columns axially loaded by concentric compression loading. It was found that the existence of steel-fibers could delay the spalling of concrete cover and improved the strain ability and ductility; the application of eccentric axial loading produced a significant variation in the maximum load, ultimate strength, and failure manners.

Al-Shaarbaf et al. [9] investigated the influence of varying hollow diameter inside slender columns on their loading capacity and cracking load. It was found that the effect of hollow ratio on columns loaded axially by eccentric loading of small eccentricities was more than the influence of hollow ratio of columns which reduced the loading capacity for the columns. Kassim and Ahmad [10] studied the strength decrease produced in short braced columns and the influence of the factors which may increase or reduce the strength change. It was found that altering the hole diameter into the columns cross section had main important effect on loading capacities, such that a 5 and $1.8 \%$ decrease in the area of cross section produced a drop of 20 and $10 \%$ in strength capability, correspondingly and increasing the concrete grade and the reinforcing steel ratio didn't reveal a significant effect, while the spacing of ties had a slight effect on the results.

In fact, the number of experimental works dealing with tests on slender columns is limited in comparison with those on stub columns. Though it was found that many studies had been focused on the behavior of short columns under concentric load as Fadhil [11]; Ali and Mohammed [12]; Ahmed et al. [13]; Alkafaji [14], while a few researches was dealing with slender columns especially that are subjected to eccentric loading (axial load with bending moment) as Al-Najafi [15] and other researchers focused on the hollow bridge columns. Therefore, the present study is devoted to the behavior and load carrying capacity of reinforced self-compacted concrete slender columns having longitudinal hollow hiding PVC pipe in their cross sections under eccentric loads considering some important.

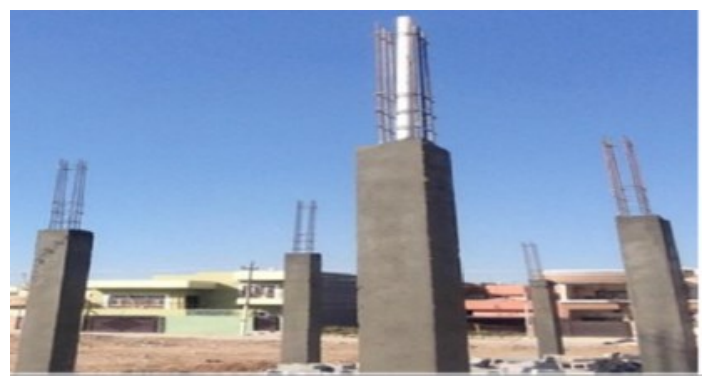

Figure 1: Inner rain drainage pipe placed inside the columns

Preparing the Column Specimens and Testing Program 


\section{Sample description}

Seven reinforced concrete hollow slender columns with different hollow shapes and two solid columns were casted and tested to assess the influence of cross sectional area loss on the loading resistance. In other word, to estimate the loading carrying capacity of such members which contain longitudinal hollow inside their cross-sectional area and to study the influence of the hollow shape and loading eccentricity, while concrete compressive strength, longitudinal and ties reinforcing bars, and overall column dimensions were kept constant.

The tested columns were of $(150 \times 150 \mathrm{~mm})$ cross section and effective length of $1300 \mathrm{~mm}$, and had a bracket at each end to make possibility of applying eccentric loading.

Figure 2 depicts a typical column with detailing and steel reinforcing bars arrangement. The columns were classified into two groups; each group involved one solid as reference and the rest with central holes of circular, square and diamond shape. The hollow area was kept nearly constant about $11 \%$ of cross sectional area of the column. The eccentricity of loading was $50 \mathrm{~mm}$ for the first group and $150 \mathrm{~mm}$ for the second group, see Table I.

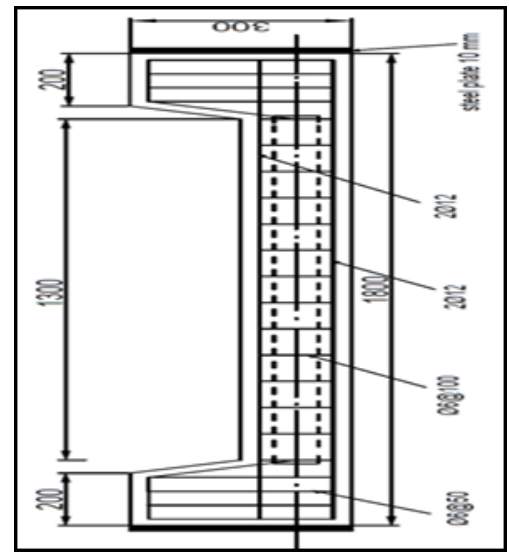

Figure 2: Detailing view of typical column

TABLE I: Columns description

\begin{tabular}{cccc}
\hline \hline Column designation & Hole shape & Hollow ratio (\%) & "Eccentricity"(mm) \\
\hline C1 & Solid & NA & 50 \\
\hline C2 & Solid & NA & 150 \\
\hline C3 & Circular & 11 & 50 \\
\hline C4 & Circular & 11 & 150 \\
\hline C5 & Square & 11 & 50 \\
\hline C6 & Square & 11 & 50 \\
\hline C7 & Diamond & 11 & 150 \\
\hline C & Diamond & 11 & 150 \\
\hline $\mathrm{C}_{\mathrm{add}}$ & Circular & 21 & \\
\hline
\end{tabular}

\section{Concrete Mix Proportions}

Requirements of fresh concrete, as filling ability, viscosity, and passing ability, were directed by means of slump flow and $\mathrm{T}_{50} \mathrm{~cm}, \mathrm{~V}$-Funnel and V-Funnel at $\mathrm{T}_{5}$ minutes, J-Ring and L-Box tests, agreeing to that of ASTM [16] standard and European Federation of National Associations for Representing SCC provisions and guidelines (EFNARC) [17]. Accordingly, in this study, the content of cement was $400 \mathrm{~kg} / \mathrm{m} 3$, fine aggregate was $850 \mathrm{~kg} / \mathrm{m}^{3}$; coarse aggregate was $850 \mathrm{~kg} / \mathrm{m}^{3}$; limestone powder was $100 \mathrm{~kg} / \mathrm{m}^{3}$; and water content was $152 \mathrm{~L} / \mathrm{m}^{3}$. The super-plasticizer content was $5.0 \mathrm{~L} / \mathrm{m}^{3}$ (1.25 liter per $100 \mathrm{~kg}$ of cement) and the water/powder ratio was 0.30 , while water/cement ratio was 0.38 .

\section{Preparation of Specimens}

The concrete grade was the same for all columns and wasn't considered as a variable so the mix design was kept constant. It was monitored using control cylinders of $200 \mathrm{~mm}$ long and $100 \mathrm{~mm}$ in diameter and $100 \times 100 \times 100 \mathrm{~mm}$ cubes and the average compressive strength $\left(\mathrm{f}_{\mathrm{c}}\right)$ was found to be 
(41.2 MPa) and (50.2 MPa) respectively, which was nearly the design strength. Column specimens are shown in Figure 3, which prepared to have a hole in the center line of column by hiding a PVC pipe of $55 \mathrm{~mm}$ diameter placed longitudinally, and of $50 \mathrm{~mm}$ side dimension for square and lozenge (square but rotated with $45^{\circ}$ ) hole shapes, see Figure 4 . The yield strength $\left(f_{y}\right)$ of longitudinal and tie reinforcing steel bars was 595 and $565 \mathrm{MPa}$ respectively according to the required test in the laboratory.

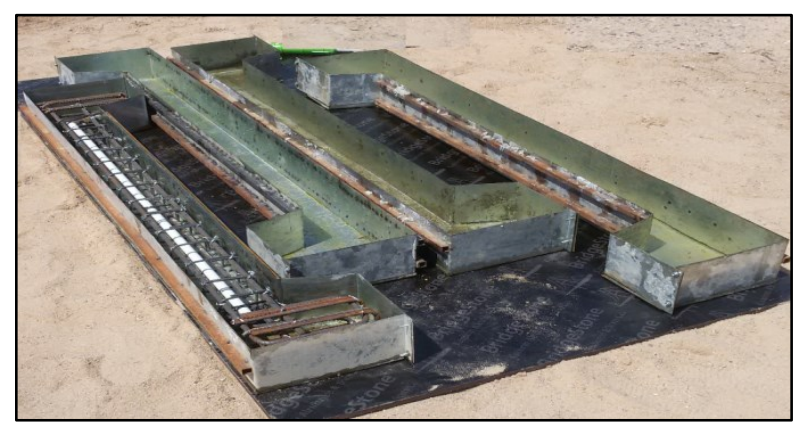

Figure 3: Reinforcement cage with a PVC pipe inside the formwork of each group

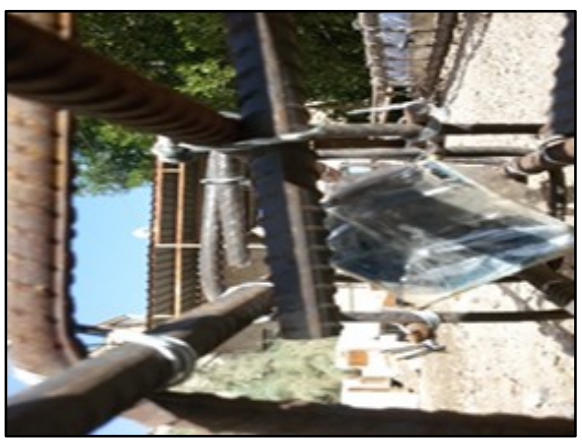

Figure 4: Steel reinforcement cage with a lozenge tube

\section{TEST MEASUREMENTS ANd InSTRUMENTATIONS}

Three dial gauges of an accuracy of $0.01 \mathrm{~mm}$ were positioned to calculate the lateral deflection for tested column at each load stage, which were equally positioned on the surface of the column as depicted in Figure 5. To get the clear lateral deflection $(\square)$ was obtained by subtracting the mean reading of top and bottom gauges from the reading of the central dial gauge of the tested column. In addition to one more identical dial gauge to calculate the vertical deflection.

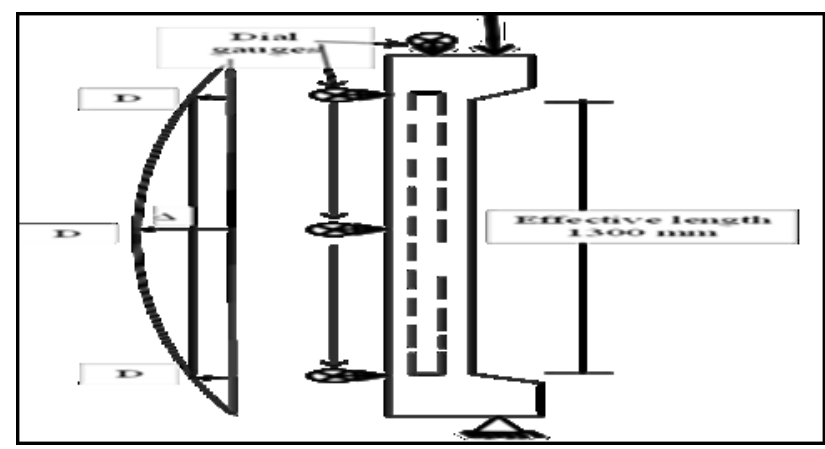

Figure 5: Test settings of dial gauges and loading of columns

The application of load was done by a universal testing machine which satisfies the test requirements of this work. Columns were placed perpendicularly and axially loaded with an eccentric load of 50 and $150 \mathrm{~mm}$ eccentricity. The ends of columns were positioned to the frame to be like pinned supports and had the same eccentricity to make the same point of load application that it assured the similar applied moment amount along column length. 


\section{INFLUENCE OF Hollow SHAPE ON THE BEHAVIOR OF COLUMNS UNDER ECCENTRIC LOADING}

The effect of using different hollow shapes was studied considering the loading capacity and lateral and longitudinal deflections of the columns under the application of eccentric load of $50 \mathrm{~mm}$ and $150 \mathrm{~mm}$ eccentricities. So, the considered variable was hole shapes, which were the circular of $56 \mathrm{~mm}$ diameter; the square and diamond of 50 side dimensions. It was observed a typical failure mode for all the tested columns which was the local buckling mode of the longitudinal reinforcement and as expected, the main effect of the holes is a decrease in the column loading capacity. All specimens were described by initiating the development of cracks at the tension side around the same location and by increasing the loading, the stresses increased in the tensile reinforcement which lead a shifting of the neutral axis to the compression side.

Tables II and III show the cracking load and the ultimate load values of all the tested columns. Figures (6-9) reveal the effect of the different hole shapes on the behavior of the columns in each group respectively. Accordingly, Figures 6 and 7 deal with the effect of eccentric loading with $50 \mathrm{~mm}$ and $150 \mathrm{~mm}$ eccentricity on the vertical deflection which represent the longitudinal shortening for the tested columns in the first and the second group respectively. While Figures 8 and 9 show the effect of eccentric loading with $50 \mathrm{~mm}$ and $150 \mathrm{~mm}$ eccentricities on the lateral deflection at mid-height of columns in the two groups.

In general, it was noticed a similar behavior of all the tested columns, and for first group of columns which had small eccentricity, the initial crack was formed at column tensile side at high levels of loading because the governing influence is the application of compression loading rather than the bending moment. Accordingly, the tension longitudinal reinforcing steel in all columns had minor stresses value up to about (100) $\mathrm{kN}$ loading level since the governing mode of failure was the compression mode. For the reason that the column is identified as long column as stated by Code ACI318-14 provisions [18] and the eccentricity of the loading is not high. Likewise, in group two which had larger eccentricity the columns were characterized also by the development and growing of cracks in the tension side, and by the time that longitudinal reinforced steel was in tension, the cracks layout of the column was distributed, causing a shift of the neutral axis to the compression side. Consequently, in this case the holes are out of cracking zone of the cross sectional area, that decreases loading capacity of these columns.

It was obvious that the hollow isn't the reason of early instability but their existence was practically accelerating instability in slender columns. On the other hand, overall stiffness decrease affected by a small hollow is not likely to alter the buckling form of columns in any significant mode. When a column containing a hollow at the center of its cross sectional area was subjected to an eccentric loading with high eccentricity, i.e. applying large moment, the moment was resisted by a small compression area and a wide cracked area of column cross section which is theoretically neglected in strength calculation. Consequently, it was noticed a decreasing in the effect of the hole on the performance of the columns of this group, which may be attributed to considering a large loading eccentricity of $150 \mathrm{~mm}$. So, all columns of the second group were characterized by a tension failure type and the influence of the hollow may be insignificant since it was mostly situated in the tension portion of cross-section, this point marks the unimportant effect of the hole shape on the column strength. For comparison purposes and to enhance the above conclusion, one more test named (Cadd) was performed on the same collection for the circular hole with hollow ratio of $21 \%$ and found the ultimate load was decreased by $6.5 \%$. The influence of hollow ratio on a column subjected to an eccentric load of low eccentricity more than the effect of high eccentricity considering the same hollow ratio, which is well agree with that found by Al-Shaarbaf et.al. (2018). It may be attributed to most of column cross sectional area was subjected to compression loading. For all tests, the deformed shape noticed clearly for the ultimate load, which revealed a single curvature, and it was detected a local buckling of the longitudinal reinforcing bars at the ultimate strength. Figures 10 and 11 show the failure mode for columns under eccentric load of 50 and $150 \mathrm{~mm}$ eccentricities respectively.

TABLE II: Crack and ultimate loads of tested columns (considering 50mm eccentricity) 


\begin{tabular}{cccc}
\hline \hline $\begin{array}{c}\text { Column } \\
\text { designation }\end{array}$ & $\begin{array}{c}\text { First } \\
\text { Crack } \\
\text { load } \\
\boldsymbol{p}_{\boldsymbol{c r}}(\mathbf{k N})\end{array}$ & $\begin{array}{c}\text { Ultimate } \\
\text { load } \\
\boldsymbol{p}_{\boldsymbol{u}}(\mathbf{k N})\end{array}$ & $\begin{array}{c}\text { \% of } \\
\text { reduction } \\
\text { in } \boldsymbol{p}_{\boldsymbol{u}}\end{array}$ \\
\hline $\mathrm{C} 1$ & 142 & 302.0 & 0.00 \\
\hline $\mathrm{C} 3$ & 129 & 287.1 & 5.0 \\
\hline $\mathrm{C} 5$ & 133 & 294.6 & 2.5 \\
\hline $\mathrm{C} 7$ & 126 & 282.0 & 6.6 \\
\hline
\end{tabular}

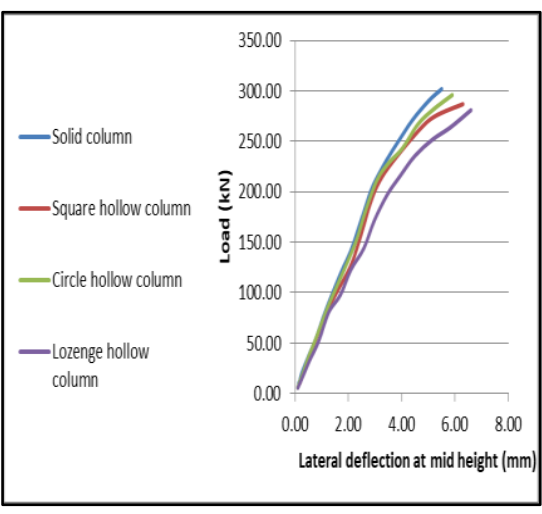

Figure 6: Lateral deflection at mid height in different shapes of holes at $50 \mathrm{~mm}$ eccentricity

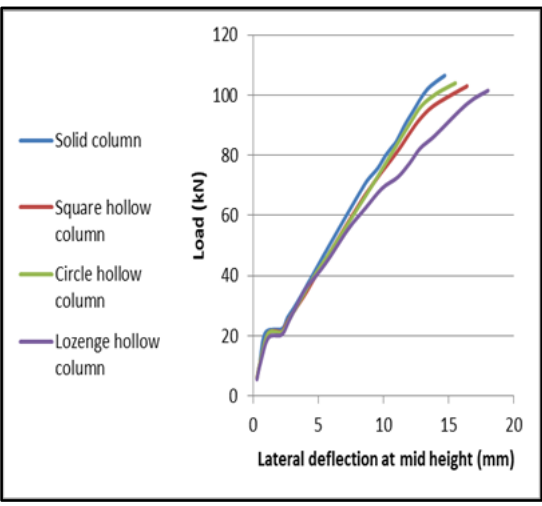

figure 7: Lateral deflection at mid height in different types of holes at $150 \mathbf{~ m m}$ eccentricity

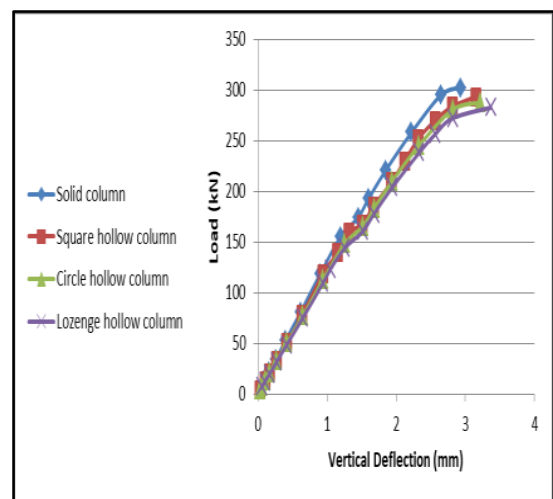

Figure 8: Vertical deflection in different types of holes at $50 \mathrm{~mm}$ eccentricity 


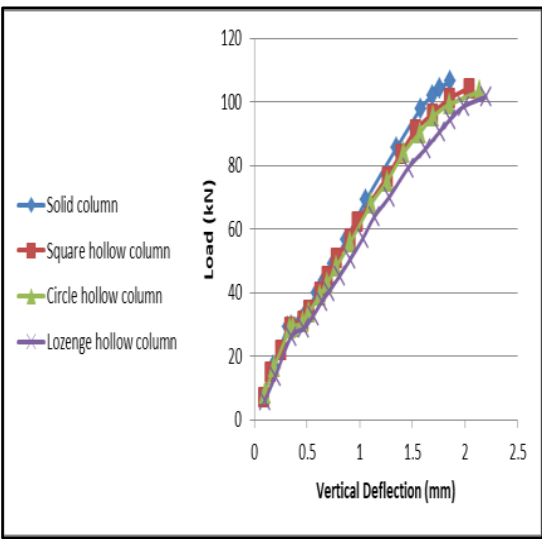

Figure 9: Vertical deflection in different types of holes at $150 \mathrm{~mm}$ eccentricity

TABLE III: $\quad$ Crack and ultimate loads of columns of group one (considering 150mm)

\begin{tabular}{cccc}
\hline \hline $\begin{array}{c}\text { Column } \\
\text { designation }\end{array}$ & $\begin{array}{c}\text { First } \\
\text { Crack } \\
\text { load } \\
\boldsymbol{p}_{\boldsymbol{c r}}(\mathbf{k N})\end{array}$ & $\begin{array}{c}\text { Ultimate } \\
\text { load } \\
\boldsymbol{p}_{\boldsymbol{u}}(\mathbf{k N})\end{array}$ & $\begin{array}{c}\text { \% of } \\
\text { decreasing in } \boldsymbol{p}_{\boldsymbol{u}}\end{array}$ \\
\hline $\mathrm{C} 2$ & 23.0 & 106.5 & 0.0 \\
\hline $\mathrm{C} 4$ & 22.5 & 103.1 & 3.2 \\
\hline $\mathrm{C} 6$ & 22.7 & 104.2 & 2.2 \\
\hline $\mathrm{C} 8$ & 22.2 & 101.5 & 4.7 \\
\hline $\mathrm{C}_{\mathrm{add}}$ & 22.0 & 99.6 & 6.5 \\
\hline
\end{tabular}

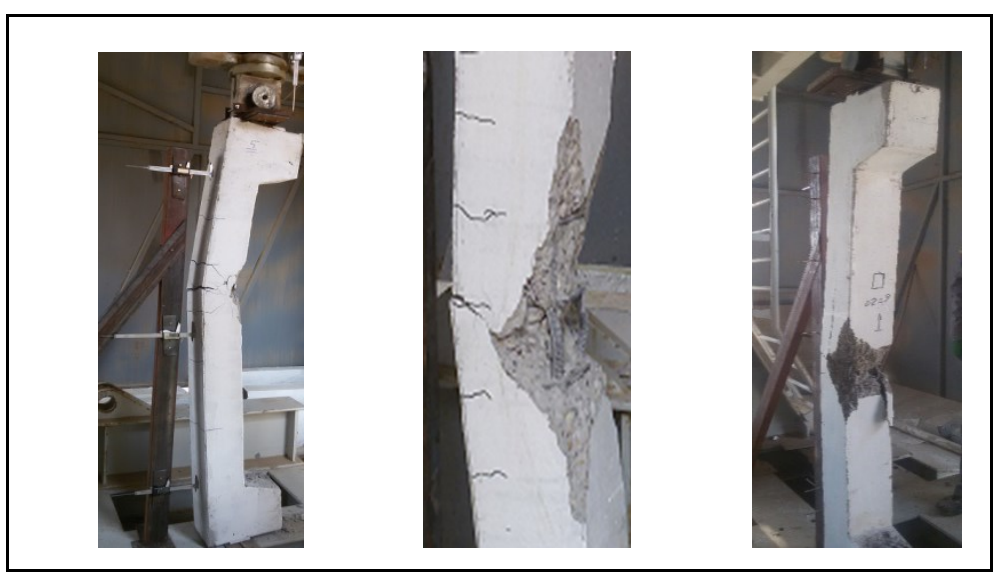

Figure 9: Failure modes for tested columns under eccentric load of $50 \mathrm{~mm}$

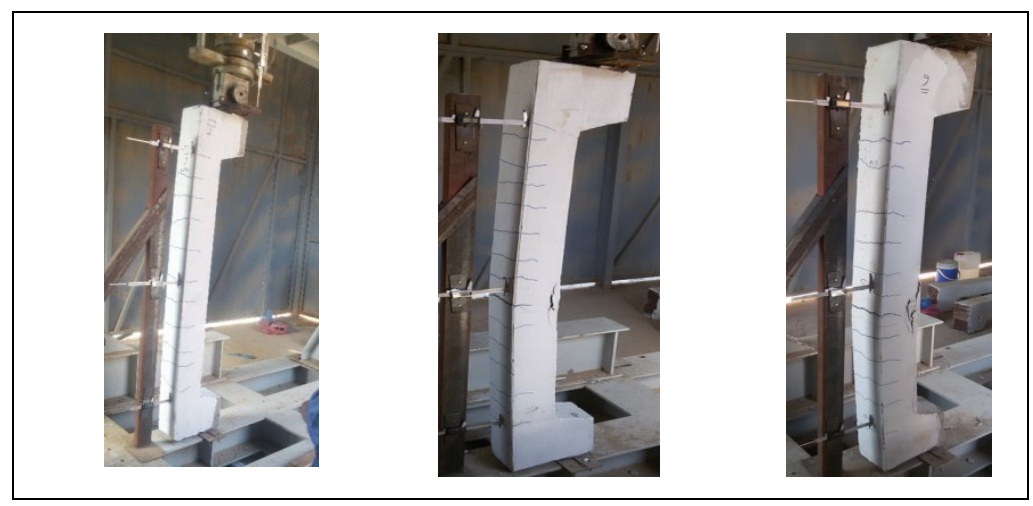

Figure 10: Failure modes for tested columns under eccentric load of $150 \mathbf{~ m m}$ 


\section{Conclusions}

1) Same tendency was noticed in the behavior of columns of the same length and subjected to eccentric loading in terms of load-deflection when different shapes of central holes were considered.

2) For higher ratio of load eccentricity $(e / h=1.0)$, changing the hole shape or area within the cross-sectional area of a slender column, has an insignificant effect on its loading capacity.

3) As expected, the eccentricity of hole positions or load applications has a significant effect on the behavior and load carrying capacity of columns.

4) Under higher eccentricity loading ratio of $(\mathrm{e} / \mathrm{h}=1.0)$, the slender columns revealed tension failure manner and the effect of hollow may be unimportant, While under small ratio of $(\mathrm{e} / \mathrm{h}=0.33)$ had compression failure manner.

5) The existence of longitudinal hole in a slender column subjected to an eccentrically loading significantly decreases its ultimate loading capacity. Accordingly, when moving the longitudinal hollow positioned in the central of cross-sectional area towards the compression side, the reduction in the load carrying capacity is increased.

\section{References}

[1] T. H. Han, J. M. Stallings, S. K. Cho, and Y. J. Kang, "Behavior of a hollow RC column with an internal tube." Magazine of Concrete Research, 62, No.1, Jan., 25-38, 2010.

[2] F. G. Mohsen, H. S. Morteza, and H. Kazemi, "Effect of core drilling on load carrying capacity of RC column” Indian Journal Fundamental of Applied Life Science. 5 (S1): 940-945, 2015.

[3] A. Murugesan, and A. Narayanan, "Influence of a longitudinal circular hole on flexural strength of reinforced concrete beams." Practice Periodical on Structural Design and Construction (C) ASCE, 22 (2): $04016021,2016$.

[4] J. Bakhteri, and S. A. Iskandar, "Experimental Study of Reinforced Concrete Columns Concealing Rain Water Pipe" Jurnal Teknologi, Vol. 43(B), pp. 13-26, December 2005.

[5] G. P. Lignola, A. Porta, G. Manfredi, and E. Cosenza, "Experimental Performance of RC Hollow Columns Confined with CFRP", Journal of Composites for Construction, ASCE, Vol. 11, No. 1, pp. 42-49, JanuaryFebruary 2007.

[6] V. Yazici and M. N. S. Hadi," Axial Load-Bending Moment Diagram of Carbon FRP Wrapped Hollow Core Reinforced Concrete Columns" Journal of Composites for Construction, ASCE, Vol. 13, No. 4, pp. 262-268, August 2009.

[7] L. Galano, and A. Vignoli, " Strength and Ductility of HSC and SCC Slender Columns Subjected to ShortTerm Eccentric Load", ACI Structural Journal, Vol. 105, No. 3, pp. 259-269, May- June 2008.

[8] G. Campione, M. Fossetti, and M. Papia, "Behavior Fiber-Reinforced Concrete Columns under Eccentrically Compressive Load" ACI Structural Journal, Vol.107, No. 3, pp. 272-280, May-June 2010.

[9] I. A. S. Al-Shaarbaf, M. J. H. Al-zubaidi, E. A. A. Al- Zaidy "Effect of Hollowing Ratio on the Behavior of Hollow Self-Compacting Reinforced Concrete Slender Column Under Eccentric Loading" International Journal of Engineering \& Technology, 7 (4.20) 390-394, 2018.

[10] M. M. Kassim and Sh. A. Ahmad "Strength Evaluation of Concrete Columns with Cross-Sectional Holes" Practice Periodical on Structural Design and Construction, ASCE, 23(4): 04018027, 2018.

[11] Fadhil "Experimental Investigation of Hollow Square Reactive Powder Concrete Columns Filled with Normal Concrete" M.Sc. Thesis, University of Technology, 2017, pp. 144.

[12] A. Y. Ali and Mohammed Z. S. "Strength Evaluation of Hybrid Reinforced Concrete Columns under Eccentric Loads" Engineering and Technology Journal, Vol. 36, Part A, No. 4, 2018.

[13] A. A. Ahmed, F. A. Alkhazraji, and S. M. Omer "Experimental study of Circular Short Columns made from Reactive Powder Concrete" Engineering and Technology Journal, Vol.34, Part (A), No.9,2016.

[14] M. M. K. Alkafaji "Structural Performance of Short Square Self Compacting Concrete Columns in Fire" Engineering and Technology Journal, Vol.33, Part (A), No.1,2015.

[15] A. H. M. Al-Najafi "Influence of Uniaxial Loading on the Strength of Slender Columns" Engineering and Technology Journal, Vol.34,Part (A), No.8,2016. 
[16] ASTM-C1611/C1611M-14, "Standard Test Method for Slump Flow of Self-Consolidating Concrete" 1, 6 pp., 2014.

[17] EFNARC, "The European Guidelines for Self-Compacting Concrete, Specification, Production and Use" Eur. Proj. Group, http//www.efnarc.org, May, 2005.

[18] ACI 318M-14, "Building Code Requirements for Structural Concrete and Commentary, American Concrete Institute, 524 pp, 2014. 